\title{
Analisis Nilai Etika Tolong Menolong dalam Novel Harga Sebuah Percaya Karya Tere Liye
}

\author{
Erlina Zahar*, Sujoko \\ Fakultas Keguruan dan Ilmu Pendidikan Universitas Batanghari Jambi \\ *Correspondence email: erlinazahar@unbari.ac.id
}

\begin{abstract}
This study aims to analyze the ethical value of helping in the novel Harga Sebuah Percaya by Tere Liye. This type of research is literary research, which is descriptive qualitative. The research data are taken from the novel Harga Sebuah Percaya by Tere Liye, namely words, sentences, and paragraphs related to the ethical value of helping to help. The data source of this research is the novel Harga Sebuah Percaya by Tere Liye. The data collection technique in this research is to use documentation and literature studies to analyze the contents of a novel, especially the ethical value of helping to help in the novel Harga Sebuah Percaya by Tere Liye. The results of the study show that the ethical value of helping to help contained in the Harga Sebuah Percaya by Tere Liye is 27 quotes.
\end{abstract}

Keywords: Analysis; Please Help; Price A Believe

\section{PENDAHULUAN}

Karya sastra dijadikan media atau wadah bagi sastrawan untuk menyampaikan pikiran, perasaan, gagasan dan ide melalui lingkungan yang berada di sekelilingnya. Karya sastra sebagai hasil cipta sastrawan menarik untuk dibaca, karena karya sastra berisi ungkapan pikiran dan perasaan tentang hidup dan kehidupan manusia. Perihal kehidupan manusia yang dikisahkan dalam cerita satra dibingkai sastrawan dengan daya kreatifitas dan dibungkus dengan imajinasi yang tinggi, sehingga karya sastra serasa gambaran dalam kehidupan nyata. Dalam mengungkapkan pikiran dan rasanya ke dalam karya sastra, sastrawan menggunakan bahasa yang estetis. Dengan begitu karya sastra menjadi sebuah bacaan yang digemari penikmatnya.

Sebagai hasil seni kreatif sastrawan, karya sastra dapat menjadi media hiburan serta obat pelipur lara dari rutinitas kehidupan manusia. Dengan hiburan yang disuguhkan sastrawan dalam karyanya dapat memberikan kegembiraan dan kepuasan batin bagi para penikmat sastra. Selain itu, karya sastra dapat dijadikan sebagai sarana untuk menuangkan isi hati dan pikiran dalam sebuah tulisan yang bernilai seni ini. Sedangkan substansi cerita sastra yang dikemas dengan sumber kehidupan manusia akan berdampak terhadap pedoman hidup bagi penikmat sastra, sehingga membaca karya sastra bernilai positif bagi pembaca. Karya sastra memiliki beberapa jenis salah satunya prosa yang berbentuk novel.

Novel merupakan jenis prosa yang mengisahkan cerita dengan menggambarkan perilaku tokohnya yang mirip dengan kehidupan di dalam masyarakat nyata. Novel bersifat fiktif tetapi dengan kepiawaian pengarang, novel tersebut bisa tampak seolah-olah nyata. Dengan begitu novel banyak digemari penikmatnya. Kisah hidup manusia yang dikemas dalam novel bisa menjadi cermin hidup bagi pembacanya. Novel merupakan gambaran kehidupan baik yang pernah dialami pembaca, dialami sastrawan dan yang terjadi pada masyarakat nyata. Selain sebagai media hiburan, novel juga bisa menjadi pelajaran hidup dalam bagi penikmatnya.

Novel memiliki dua unsur pembangun, yaitu unsur instrinsik dan unsur ekstrinsik. Unsur instrinsik adalah unsur yang berada di dalam sebuah karya sastra yang terdiri dari tokoh, penokohan, latar, alur, gaya bahasa, sudut pandang serta amanat. Sedangkan, unsur ekstrinsik adalah unsur yang berada di luar sebuah karya sastra. Unsur ekstrinsik berupa nilai agama, nilai budaya, nilai sosial, nilai etika, dan lain-lain.

Etika mempersoalkan bagaimana semestinya manusia bertindak tentang pertimbangkan baik dan buruk suatu tingkah laku manusia Seperti kita ketahui di dalam kehidupan masyarakat, kita tidak pernah lepas dari tingkah laku atau etika seseorang. Abdullah (2006) berpendapat di dalam nilai etika terdapat etika tolongmenolong. Tolong menolong dalam lingkungan masyarakat sangat penting. Seseorang hidup di dalam lingkungan masyarakat wajib tolong menolong apabila seseorang mempunyai hubungan kemanusiaan. Bentuk dari tolong menolong dalam masyarakat bisa berupa material, tenaga, dan moral.

Pengaruh globalisasi banyak mempengaruhi pola pikir masyarakat saat ini. Masyarakat banyak cenderung individualis dan lebih memikirkan kebutuhan sendiri tanpa memikirkan manusia lain di sekitarnya. Padahal setiap manusia merupakan mahluk sosial yang membutuhkan bantuan manusia lain. Kurangnya sikap tolong-menolong dapat menimbulkan sifat masa bodoh dan tidak mau lagi perduli dengan apa yang terjadi disekitarnya baik itu pada keluarga, tetangga, maupun sahabat. Akibatnya berdampak pada kondisi sosial di masyarakat. Hal ini mengindikasikan etika manusia telah bergeser yang tidak sesuai lagi dengan harkat hidup kemanusiaan yang seyogyanya saling menolong. 
Berdasarkan fenomena sosial di atas penulis ingin memaparkan nilai etika tolong menolong dalam novel Harga Sebuah Percaya karya Tere Liye. Novel ini banyak mengandung nilai-nilai postitif yang dapat diambil oleh pembaca terutama tentang nilai etika tolong menolong. Selain itu, penulis juga tertarik dengan cerita yang disajikan oleh pengarangnya.

Novel Harga Sebuah Percaya ditulis oleh Tere Liye. Novel Harga Sebuah Percaya karya Tere Liye merupakan salah satu karya sastra yang penulis jadikan sebagai penelitian. Novel tersebut dirilis pada bulan Mei tahun 2017. Novel ini diterbitkan oleh penerbit Mahaka Publishing. Novel ini berjumlah 299 halaman.

Tere Liye adalah seorang novelis. Tidak sedikit karya Tere Liye yang sudah di angkat ke layar kaca, yaitu Hafalan Sholat Delisa dan Moga Bunda Disayang Allah. Novel-novel yang telah ditulis oleh Tere Liye diantaranya Hujan, Berjuta Rasanya, Tentang Kamu, Bintang, Negeri di Ujung Tanduk. Penulis telah membaca beberapa dari karya Tere Liye, dan penulis senang membacanya. Oleh karena itu, penulis tertarik meneliti salah satu dari karya Tere Liye, yaitu adalah novel Harga Sebuah Percaya karya Tere Liye yang dirilis pada tahun 2017.

Tujuan penelitian merupakan rumusan kalimat yang menunjukkan arah dari hasil yang akan diperoleh. Dengan tujuan penelitian yang jelas suatu penelitian akan menjadi terarah. Berdasarkan pertanyaan penelitian yang telah dikemukakan di atas, maka tujuan penelitian ini adalah untuk menganalisis nilai etika tolong menolong yang terdapat dalam novel Harga Sebuah Percaya karya Tere Liye.

\section{METODE}

Jenis penelitian sangatlah penting untuk mencapai tujuan dalam penelitian. Jenis penelitian salah satu cara untuk mendapatkan data dengan kegunaan tertentu dan tujuan tertentu. Menurut Siswantoro (2014) "Jenis penelitian adalah cara yang digunakan seorang peneliti di dalam usaha memecahkan masalah yang diteliti". Jenis penelitian yang digunakan dalam penelitian ini adalah deskriptif. Jenis penelitian deskriptif mengarah pada permasalahan aktual. Noor (2011) mengatakan bahwa "Jenis deskriptif merupakan penelitian yang memusatkan pada masalah aktual sebagaimana adanya pada penelitian berlangsung yang diselidiki dengan mendeskripsikan peristiwa dan kejadian yang menjadi pusat perhatian tanpa memberikan perhatian khusus terhadap peristiwa tersebut". Penelitian deskriptif ini mengungkapkan fakta-fakta secara nyata sebagai mana adanya dengan cara mendeskripsikan. Jenis penelitian deskriptif menuturkan dan memecahkan masalah yang ada di dalam penelitian. Menurut Nawawi (dalam Siswantoro, 2014) "Penelitian deskriptif adalah prosedur pemecahan masalah yang diselidiki dengan menggambarkan atau melukiskan keadaan subjek atau abjek berdasarkan fakta-fakta yang tampak atau sebagaimana adanya". Deskriptif menuntut peneliti sastra mengungkap fakta sesuai dengan apa adanya. Penelitian deskriptif dapat dilakukan dengan penerapan metode kualitatif.

\section{Data}

Data merupakan unsur dan syarat utama dalam penelitian untuk dijadikan bahan analisis. Siswantoro (2010:70) mengatakan bahwa "Data adalah sumber informasi yang akan diseleksi sebagai bahan analisis". Data dalam penelitian ini adalah semua kutipan-kutipan yang berhubungan dengan nilai etika tolong menolong dalam novel Harga Sebuah Percaya karya Tere Liye. Kutipan data penelitian ini dapat berupa kata, kalimat, paragraf yang terkait dengan nilai etika tolong menolong yang terdapat dalam novel Harga Sebuah Percaya karya Tere Liye.

\section{Sumber Data}

Sumber data merupakan darimana data penelitian diperoleh. Menurut Siswantoro (2010) "Sumber data terkait dengan subjek peneliitan dari mana data diperoleh". Sumber data penelitian ini adalah novel Harga Sebuah Percaya karya Tere Liye yang bukunya diperoleh di toko Gramedia. Novel Harga Sebuah Percaya diterbitkan oleh Mahaka Publishing pada tahun 2017. Novel ini berjumlah 298 halaman. Novel ini berukuran $13,5 \mathrm{~cm}$ x $20,5 \mathrm{~cm}$. Sampul novel ini berwarna kuning, hijau, putih, biru sehingga menarik untuk dipandang.

Teknik pengumpulan data dalam penelitian ini dilakukan berdasarkan langkah-langkah pendekatan struktural yang diacu menurut pandangan Levi-Strauss. Menurut Levi-Strauss (dalam Rafiek, 2010) langkahlangkah pendekatan struktural adalah sebagai berikut:

1. Membaca keseluruhan cerita terlebih dahulu. Dari membaca diperoleh pengetahuan, kepekaan peneliti agar dapat menghayati dan memahami data secara mendalam dan kesan tentang cerita, di dalam novel Harga Sebuah Percaya karya Tere Liye.

2. Membaca secara kritis, teliti, dan berulang-ulang tentag keseluruhan novel Harga Sebuah Percaya karya Tere Liye.

3. Kemudian peneliti menandai bagian kata-kata, kalimat, paragraf yang berhubungan dengan nilai etika tolong menolong dalam novel Harga Sebuah Percaya karya Tere Liye.

4. Lalu peneliti mencatat bagian data yang berhubungan langsung terhadap nilai etika tolong menolong dalam novel Harga Sebuah Percaya karya Tere Liye.

5. Setelah data terkumpul, peneliti mengklasifikasi data sesuai dengan nilai etika tolong menolong dalam novel Harga Sebuah Percaya karya Tere Liye.

Teknik analisis data merupakan langkah yang strategis dalam sebuah penelitian. Menurut Siswantoro (2014) "Teknik analisis yang dilakukan dalam 
pemaparan dalam bentuk deskriptif terhadap masingmasing data secara fungsional dan rasional". Setelah semua data dari novel Harga Sebuah Percaya karya Tere Liye terkumpul baik berupa data kata-kata, kalimatkalimat, yang menjadi paragraf, baik paragraf dialog maupun paragraf narasi yang berisikan nilai etika tolong menolong. Yang kemudian diperkuat dengan berbagai kutipan-kutipan dalam novel Harga Sebuah Percaya karya Tere Liye dan kemudian membuat kesimpulan dari masing-masing masalah, dalam hal ini beurupa kutipan dalam novel Harga Sebuah Percaya karya Tere Liye serta menganalisis data Setelah data terkumpul. Langkah-langkah menganalisis sebagai berikut:

1. Data yang berupa kutipan-kutipan nilai etika tolong menolong kemudian ditabulasikan ke dalam tabel tabulasi data untuk dianalisis dengan format tabel seperti di bawah ini.

Tabel 1. Analisis Data Nilai Etika Tolong Menolong dalam Novel Harga Sebuah Percaya karya Tere Liye

\begin{tabular}{cccc}
\hline & Kutipan nilai Etika Tolong & \\
No & Menolong & Analisis & Halaman \\
\hline 1. & & \\
2. & & \\
\hline
\end{tabular}

2. Langkah selanjutnya data tabulasi di atas peneliti interpretasi berdasarkan teori menurut Abdullah (2006).

3. Setelah data diinterpretasi langkah selanjutnya menganalisis data penelitian.

4. Melakukan keabsahan data dengan cara mengecek data dengan temuan lain, sehingga tidak ditemukan ketidaksesuaian antar satu dengan teori lainnya.

5. Setelah dilakukan keabsahan data selanjutnya peneliti mendeskripsikan nilai etika tolong menolong yang terdapat dalam novel Harga Sebuah Percaya karya Tere Liye.

6. Langkah terakhir, merumuskan kesimpulan.

\section{HASIL DAN PEMBAHASAN}

Gambaran nilai etika tolong menolong tokoh Hepi di dalam novel Harga Sebuah Percaya karya Tere Liye ini menggambarkan bahwa tokoh-tokoh di dalam novel memiliki rasa tolong-menolong antar sesama, hal ini dapat terlihat dari terdapatnya kutipan-kutipan yang memperlihatkan bahwa di dalam novel Harga Sebuah Percaya karya Tere Liye banyak sekali tokoh-tokoh menolong yang saling tolong-menolong, bahu-membahu antar sesama di dalam kesulitan baik dalam bentuk material, moral dan tenaga. Terlihat dari banyaknya kutipan etika tolong-menolong, yaitu sebanyak 27 kutipan.

Kutipan-Kutipan Nilai Etika Tolong Menolong yang terdapat dalam novel Harga Sebuah Percaya karya Tere Liya

1. "Tolong... Tolonglah aku tuan!" pria itu mendesah tangannya lembut mengelus sayap seekor capung yang mengembang di depannya. Tetapi Jim tahu, pria asing berwajah menyenangkan ini akan membantunya. Entah bagaimana ia melakukannya. (HSP:48)

2. "Baiklah, seperti yang kukatakan sebelumnya, semakin tua dunia semakin sulit untuk mencari pengukir dongeng. Kuberikan kau kesempatan keempat untuk bertemu denganku. Pergunakanlah dengan bijak, Jim. Karena itu bisa berarti menyelamatkan nyawamu. Kapan pun kau membutuhkan aku, panggilah dan aku akan datang. $(H S P: 54)$

3. "Pete Meneriaki Jim lagi dari kejauhan, Jim tidak mendengar. Ia sibuk memperhatikan gerak tangan anak di depannya. Pete mengomel, mengalah baiklah ia tidak ingin membuat si Kelasi yang menangis tiba-tiba merajuk hanya gara-gara karung gandum. Pete akhirnya membantu menggendong karung gandum yang tergeletak ke atas Pedang Langit. (HSP:68)

4. Sebulan kemudian dilewatkan Jim situasi yang belum pernah ditemukan sepanjang hidupnya. Ia merasakan semangatnya kembali. Kembali bersama auntusiasme yang besar. Pete mengajari Jim menulis dan membaca. Sebaliknya, Jim mengajari Pete memetik dawai di atas papan tersebut. (HSP:73)

5. Jim dihadang empat puluh kapal "Menunduk Jim !" Pete menarik tanganya. Jim buru-buru membungkuk di sebelah Pete, mukanya pucat. Tangannya gemeteran. Ia tidak tahu apa apa maksud ratusan kapal di depan, tapi melihatnya sungguh mengetarkan hati. (HSP:79)

6. Jim tidak sempat berfikir tentang hidup atau mati, ia nyaris pingsan, bahkan sebelum kelewang itu menyambarnya Jim berteriak ketakutan.kejadian berlangsung seperseribu detik. Ternyata yang terjengkang bukan Jim, melainkan perampok itu. Pete berdiri gagah di hadapan Jim. Memegang pedang bersimpahan darah mata melotot tajam setelah membantu Jim. (HSP:92)

7. Pete membentaknya agar segera berdiri "Ambil kelewangmu, Bodoh!” Jim tidak mendengar. Jim sudah jatuh tersungkir. Mengeluh amat dalam. Duhai lihatlah, ia baru saja membunuh. Pete mengerutu berusaha mati-matian melindungi Jim. (HSP:93)

8. "Kau harus mengorbankan Pedang langit dan kapal-kapal perang milikmu, Ramierz. Gunakanlah kamar-kamar rahasia milikmu. Dan sisanya serahkanlah kepada pemilik semesta alam. Biarkanlah kekuasaan langit menentukan takdirmu besok biarlah waktu yang memperlihatkan jalan nasibmu" "selamat berjuang Ramirez" sang Penanda. (HSP: 108)

9. Seluruh Kelasi dan prajurit yang tersisa dengan luka-luka di sekujur tubuh bekerja keras hingga 
pagi datang menjelang. Bahkan, si Mata Elang ikut membantu mengendong peluru meriam. (HSP: 109)

10. Tidak pernah Jim melihat tatapan mata bercahaya seyakin itu. Sepanjang malam, Jim sedikitpun tidak sempat mendekati Laksmana, karena seperti prajurit lainya ia sibuk membantu memindahkan peralatan peluru. (HSP:109)

11. "Dia mengukir dongeng melalui orang-orang yang dipilihnya. Menggurat dongeng yang dibutuhkan oleh dunia. Memberikan pengharapan bagi yang mendengarnya, janji kebaikan selalu menang, kejahatan selalu kalah. Jangan pernah berhenti bermimpi, agar kehidupan berjalan jauh lebih baik. Itulah tugas sang penanda. (HSP:121)

12. Sekali di taman kota, sekali dipekuburan, dan terakhir kalinya saat pria tua itu menyelamatkanya dari pasukan pemburu bayaran Beduin. Betapa semua pertemuan hanya untuk menyakinkannya tentang dongeng itu. (HSP:124)

13. Malam hari sebelum Ramirez eksekuasi, aku menyadari betapa keliru jalan yang kupilih, menyadari semua sia-sia. Tiba-tiba capung bertebangan datanglah sang penanda untuk kedua kalinya. "sang penanda jongkok, dia mengelus rambutku kemudian berkata jika pemilih semesta alam memaafkanmu besok, maka dengarkanlah kata-kataku, pergilah ke Ibukota, kau akan memulai dongeng hebat itu di sana.(HSP:128)

14. Bukan gunung itu yang penting bagi Jim. Ia tidak tertarik berdiri dipuncak Adam. Melainkan Pete, Jim menyelamatkan nyawanya di pertempuran empat puluh hari. ( $H S P: 137)$

15. Meyerahlah ruas bamboo tersebut. Hati-hati menuangkan air segar ke mulut Jim. Hangatnya air dalam ruas bamboo membantu Jim menggerakan mukanya, menatap paras gadis itu. Wajah yang cemas dan takut. (HSP:154)

16. Beruntung pagi harinya, bukan hanya gadis itu yang mendekatinya untuk memberikan minuman dari ruas bambu, juga datang Tetua kampung lainnya. Tetua kampung itu memberikan ramuan tetumbuhan, obat. Mereka melakukan itu Jim tidak tahu. Mungkin ingin menyaksikan pertunjukan ini lebih lama lagi. (HSP:157)

17. Dengan cepat Pete menebas tali-temali. Ketika semua tali terlepas, Jim justru terjatuh. Barubaru Pete menggapainya. Tidak. Jim sama sekali tidak bisa ikut dalam pelarian itu. Tubuhnya sedikit pun tidak bisa digerakkan. Kaku. Ia hanya akan menghambat lari Pete. (HSP:158)

18. Hujan batu es masih turun deras. Orang-orang tak ada yang Nampak memperlihatkan diri dalam kegelapan. Jim tak kuat lagi berdiri. Pete tertitih menggendong Jim. Lebih susah lagi dengan satu tangan memegang pedang terhunus. (HSP:159)

19. Ketika semak belukar itu sempurna tersibak. Didalamnya terdapat gua. Tingginya dua meter, lebarnya satu setengah meter. Pete menoleh memandang gadis itu. "jika kalian ingin lari. Lewat gua ini hanya ini satu-satunya jalan. Ujungnya persis persis menuju gunung di lereng belakang. Kalian akan baik-baik saja melewatinya. (HSP:160)

20. "Kita sudah jauh" Pete menjawab riang, membantu Jim meneguk air dari ruas bamboo. Jim berusaha mengingat-ngingat apa yang telah terjadi beberapa hari lalu. (HSP:166)

21. "Papan pendawaku" Jim berkata pelan melihat alat musik yang tergeletak di sebelah Pete berusaha menggapai dengan jari-jarinya yang masih gemetar, Pete membantu mengambilkan "Aku sekarang tahu betapa buruknya permainan musikku, Teman" (HSP:167)

22. Jim dan Pete membantu Kelasi Pedang Langit mengamankan geladak. Mereka beruntung, menurunkan layar tepat pada waktunya. Sayang angin puting beliung itu tetap mematahkan salah satu tiang layar. (HSP:180)

23. Laksmana Ramirez tanpa banyak bicara, langsung menebas tali-tali yang mengikat papan dan tiangtiang kerangkeng. Jim membantu melepaskan, Pete yang ikut membantu membuka kerangkeng Setelah kakinya bebas. Hanya dalam hitungan detik kerangkeng tersebut roboh. (HSP:192)

24. Sore hari, Laksamana Ramirez memutuskan untuk berlabuh. Penjelasan utusan tadi cukup. Ada yang harus dibantu. Urusan ini bukan tentang siapa yang benar siapa yang salah. Bukan pula pertikaian kepentingan. Penduduk kota Champa yang tidak berdosa harus dilindungi (HSP:202)

25. Sekejap. Kepala adik baginda sudah mengelinding di atas lantai. Pedang Jim berhenti tepat sebelum menyentuh semilir pun leher jenjang Nayla. Gadis itu roboh saking terkejutnya. Jim buru-buru meraih pinggangnya. Mendekap. (HSP:219)

26. Jim punya kesibukan baru. Menjelajahi pedalaman hutan bersama Pete dan Laksamana Ramirez membantunya banyak menyembuhkan luka kota Champa. Kenangan-kenangan itu berhasil di kunci rapat dalam hatinya.

27. 'PERGILAH JIM... Aku mohon! Kau harus menyelesaikan dongengmu, kau harus membantu Laksamana menyelesaikan dongengnya. Bantulah dia. Biarkan aku menahan mereka "Suara Pete semakin purau. Ia mulai menangis pahanya semakin sakit. Mata Jim berkaca-kaca Pete mengacungkan pedangnya Pergilah! 


\section{Pembahasan}

Nilai etika tolong menolong dalam kehidupan bermasyarakat adalah sikap yang senang menolong orang lain mengingatkan perbuatan baik dan buruk, memberikan dorongan, semangat antar sesama manusia baik dalam bentuk material maupun tenaga dan moral. Nilai etika tolong menolong dapat terlihat dari beberapa kutipan sebagai berikut:

1. “Tolong...Tolonglah aku tuan!" pria itu mendesah tanganya lembut mengelus sayap seekor capung yang mengembang di depannya. Tetapi Jim tahu, pria asing berwajah menyenangkan ini akan membantunya. Entah bagaimana ia melakukannya. (HSP:48)

Kutipan 1.1 menggambarkan Jim meminta pertolongan kepada sang penanda dari pembunuh bayaran suku Beduin. Bentuk tolong menolong yang di lakukan sang penanda kepada Jim menyelamatkanya dari suku Biduin.

2. "Baiklah, seperti yang kukatakan sebelumnya, semakin tua dunia semakin sulit untuk mencari pengukir dongeng. Kuberikan kau kesempatan keempat untuk bertemu denganku. Pergunakanlah dengan bijak, Jim. Karena itu bisa berarti menyelamatkan nyawamu. Kapan pun kau membutuhkan aku, panggilah dan aku akan datang.(HSP:54)

Kutipan 1.2 menggambarkan sang penanda memberikan kesempatan keempat untuk mempergunakanya dalam hal apapun. Bentuk tolong menolong yang dilakukan sang penanda kepada Jim bersedia membantunya ketika Jim mendapatkan kesulitan.

3. "Pete Meneriaki Jim lagi dari kejauhan, Jim tidak mendengar. Ia sibuk memperhatikan gerak tangan anak di depannya. Pete mengomel, mengalah baiklah ia tidak ingin membuat si Kelasi yang menangis tiba-tiba merajuk hanya gara-gara karung gandum. Pete akhirnya membantu menggendong karung gandum yang tergeletak ke atas Pedang Langit. (HSP:68)

Kutipan 1.3 menggambarkan Pete meneriaki Jim yang berhenti diperjalanan saat membawa gandum, tapi Jim tidak mendengar. Pete tidak ingin membuat Jim marah dengan begitu Jim membawa karung gandum yang ditinggalkan Jim. Bentuk tolong menolong yang dilakukan Pete terhadap Jim, yaitu mengangkat karung gandung yang dimiliki Jim.

4. Sebulan kemudian dilewatkan Jim situasi yang belum pernah ditemukan sepanjang hidupnya. Ia merasakan semangatnya kembali. Kembali bersama auntusiasme yang besar. Pete mengajari Jim menulis dan membaca. Sebaliknya, Jim mengajari Pete memetik dawai di atas papan tersebut. (HSP:73)

Kutian 1.4 menggambarkan Jim merasakan hal yang baru di dalam perjalananya. Ia merasakan hidupnya kembali. Seiring berjalanya waktu Jim dan Pete saling mengenal dan menolong satu sama lain. Bentuk tolong-menolong di lakukan oleh Jim dan Pete yang menolong antar sesama.

5. Jim dihadang empat puluh kapal "Menunduk Jim !" Pete menarik tangannya. Jim buru-buru membungkuk di sebelah Pete, mukanya pucat. Tangannya gemeteran. Ia tidak tahu apa apa maksud ratusan kapal didepan, tapi melihatnya sungguh mengetarkan hati. (HSP:79)

Kutipan 1.5 menggambarkan Pete menolong Jim dari hadangan empat puluh kapal di hadapan Jim. Bentuk tolong menolong yang dilakukan Pete terhadap Jim yaitu menolongnya di saat Jim membutuhkan bantuan.

6. Jim tidak sempat berfikir tentang hidup atau mati, ia nyaris pingsan, bahkan sebelum kelewang itu menyambarnya Jim berteriak ketakutan. Kejadian berlangsung seperseribu detik. Ternyata yang yang terjengkang bukan Jim, melainkan perampok itu. Pete berdiri gagah di hadapan Jim. Memegang pedang bersimpahan darah mata melotot tajam Setelah membantu Jim. (HSP:92)

Kutipan 1.6 menggambarkan Pete datang tepat waktu menolong Jim dari penjahat yang ingin membunuh Jim, tanpa ragu Pete memenggal kepala Penjahat untuk menyelamatkan Jim. Bentuk tolong menolong yang dilakukan Pete terhadap Jim ia menyelamatkan nyawa Jim.

7. Pete membentaknya agar segera berdiri "Ambil kelewangmu, Bodoh!” Jim tidak mendengar. Jim sudah jatuh tersungkir. Mengeluh amat dalam. Duhai lihatlah, ia baru saja membunuh. Pete mengerutu berusaha mati-matian melindungi Jim. (HSP:93)

Kutipan 1.7 menggambarkan Pete memarahi Jim karena dia merasa ketakutan untuk melawan musuh. Dan Pete sudah menghabisi musuh sendirian untuk menyelamatkan Jim. Bentuk tolong menolong yang dilakukan Pete terhadap Jim ia berusaha melindungi Jim dari musuh.

8. "Kau harus mengorbankan Pedang langit dan kapal-kapal perang milikmu, Ramierz. Gunakanlah kamar-kamar rahasia milikmu. Dan sisanya serahkanlah kepada pemilik semesta alam. Biarkanlah kekuasaan langit menentukan takdirmu besok biarlah waktu yang memperlihatkan jalan nasibmu" "selamat berjuang Ramirez" sang Penanda (HSP: 108)

Kutipan 1.8 menggambarkan sang penanda memberikan bantuan pada Ramirez atas kekacauan yang terjadi di dalam kapal. Bentuk tolong menolong yang dilakukan sang penanda pada Ramirez.

9. Seluruh Kelasi dan prajurit yang tersisa dengan luka-luka di sekujur tubuh bekerja keras hingga 
pagi dtang menjelang. Bahkan, si Mata Elang ikut membantu mengendong peluru meriam. (HSP: 109)

Kutipan 1.9 menggambarkan si Mata Elang ikut membantu mengendong peluru-peluru setelah peperangan besar terjadi. Bentuk tolong menolong yang dilakukan si Mata Elang.

10. Tidak pernah Jim melihat tatapan mata bercahaya seyakin itu. Sepanjang malam, Jim sedikitpun tidak sempat mendekati Laksmana, karena seperti prajurit lainya ia sibuk membantu memindahkan peralatan peluru. (HSP:109)

Kutipam 1.10 menggambarkan Jim membantu prajurit lainnya memindahkan peluru. Bentuk tolong menolong yang dilakukan Jim membantu prajurit.

11. "Dia mengukir dongeng melalui orang-orang yang dipilihnya. Menggurat dongeng yang dibutuhkan oleh dunia. Memberikan pengharapan bagi yang mendengarnya, janji kebaikan selalu menang, kejahatan selalu kalah. Jangan pernah berhenti bermimpi, agar kehidupan berjalan jauh lebih baik. Itulah tugas sang penanda." (HSP:121)

Kutipan 1.11 menggambarkan sang penanda memberikan harapan kepada seseorang untuk tetap bangkit dalam kesusahan dan masalah apapun akan ada jalan keluarnya bentuk tolong menolong dilakukan oleh sang penanda kepada orang-orang yang dipilihnya untuk melewati permasalahan.

12. Sekali di taman kota, sekali dipekuburan, dan terakhir kalinya saat pria tua itu menyelamatkanya dari pasukan pemburu bayaran Beduin. Betapa semua pertemuan hanya untuk menyakinkannya tentang dongeng itu. $(H S P: 124)$

Kutipan 1.12 menggambarkan sang penanda menyelamatkan Jim dari taman kota, pekuburan sampai kepemburu bayaran bentuk tolong menolong yang dilakukan sang penanda terhadap Jim yang terkena musibah.

13. Malam hari sebelum Ramirez eksekuasi, aku menyadari betapa keliru jalan yang kupilih, menyadari semua sia-sia. Tiba-tiba capung bertebangan datanglah sang penanda untuk kedua kalinya. "sang penanda jongkok, dia mengelus rambutku kemudia berkata jika pemilih semesta alam memaafkanmu besok, maka dengarkanlah kata-kataku, pergilah ke Ibukota, kau akan memulai dongeng hebat itu di sana.(HSP:128)

Kutipan 1.13 menggambarkan malam sebelum Ramirez di eksekuasi sang penanda datang menolong dan memberikan saran untuk pergi ke Ibukota. Bentuk tolong menolong yang dilakukan sang penanda kepada Ramirez untuk menyuruhnya ke Ibukota memulai hidup baru.

14. Bukan gunung itu yang penting bagi Jim. Ia tidak tertarik berdiri dipuncak Adam. Melainkan Pete,
Jim menyelamatkan nyawanya di pertempuran empat puluh hari. (HSP:137)

Kutipan 1.14 menggambarkan Jim akan menemani Pete untuk mendaki puncak Adam karena Pete telah menyelamatkan nyawanya. Bentuk tolong menolong yang dilakukan Pete terhadap Jim tidak hanya Pete Jim juga menolong Pete untuk berada di sampingnya.

15. Meyerahlah ruas bamboo tersebut. Hati-hati menuangkan air segar ke mulut Jim. Hangatnya air dalam ruas bamboo membantu Jim menggerakkan mukanya, menatap paras gadis itu. Wajah yang cemas dan takut. $(H S P: 154)$

Kutipan 1.15 menggambarkan gadis memberikan air minum dalam ruas bamboo terhadap Jim yang sudah tak berdaya lagi. Bentuk tolong menolong yang dilakukan gadis desa terhadap Jim.

16. Beruntung pagi harinya, bukan hanya gadis itu yang mendekatinya untuk memberikan minuman dari ruas bambu, juga datang Tetua kampung lainya. Tetua kampung itu memberikan ramuan tetumbuhan, obat. Mereka melakukan itu Jim tidak tahu. Mungkin ingin menyaksikan pertunjukan ini lebih lama lagi. (HSP:157).

Kutipan 1.16 menggambarkan Jim ditolong oleh gadis kampung dan tetua kampung lainya untuk menyembuhkan luka di badannya. Bentuk tolong menolong dilakukan oleh warga kampung kepada Jim.

17. Dengan cepat Pete menebas tali-temali. Ketika semua tali terlepas, Jim justru terjatuh. Barubaru Pete menggapainya. Tidak. Jim sama sekali tidak bisa ikut dalam pelarian itu. Tubuhnya sedikit pun tidak bisa digerakan. Kaku. Ia hanya akan menghambat lari Pete. (HSP:158)

Kutipan 1.17 menggambarkan Pete membantu membebaskan Jim yang sudah hampir tak berdaya lagi. Bentuk tolong menolong dilakukan Pete terhadap Jim.

18. Hujan batu es masih turun deras. Orang-orang tak ada yang Nampak memperlihatkan diri dalam kegelapan. Jim tak kuat lagi berdiri. Pete tertitih menggendong Jim. Lebih susah lagi dengan satu tangan memegang pedang terhunus. (HSP:159).

Kutipan 1.18 menggambarkan Jim dan Pete berusaha melarikan diri sebelum warga kampung mencarinya, melihat kondisi Jim yang tidak bisa berjalan Pete langsung menggendongnya meskipun pada saat itu hujan. Bentuk tolong menolong yang dilakukan Pete terhadap Jim yaitu perduli atas sesama mengerti disaat teman membutuhkan pertolongan.

19. Ketika semak belukar itu sempurna tersibak. Didalamnya terdapat gua. Tingginya dua meter, lebarnya satu setengah meter. Pete menoleh memandang gadis itu. "jika kalian ingin lari. 
Lewat gua ini hanya ini satu-satunya jalan. Ujungnya persis persis menuju gunung di lereng belakang. Kalian aka baik-baik saja melewatinya." $(H S P: 160)$

Kutipan 1.19 menggambarkan Jim dan Pete di tolong oleh gadis kampung saat hendak pergi meninggalkan kampung, diberikan jalan yang tidak diketahui oleh warga kampung. Bentuk tolong menolong yang dilakukan gadis kampung kepada Pete dan Jim.

20. "Kita sudah jauh" Pete menjawab riang, membantu Jim meneguk air dari ruas bamboo. Jim berusaha mengingat-ngingat apa yang telah terjadi beberapa hari lalu. (HSP:166)

Kutipan 1.20 menggambarkan Pete dan Jim sudah menjauh dari kampung dan Pete membantu menegukan air di bibir Jim yang baru tersadar. Bentuk tolong menolong yang dilakukan Pete terhadap Jim.

21. "Papan pendawaku" Jim berkata pelan melihat alat musik yang tergeletak disebelah Pete berusaha menggapai dengan jari-jarinya yang masih gemetar, Pete membantu mengambilkan "Aku sekarang tahu betapa buruknya permainan musikku, Teman" (HSP:167)

Kutipan 1.21 menggambarkan Pete membantu mengambil kan Jim papan pendawa karena Jim merasa gemetar jemarinya. Bentuk tolong menolong dilakukan oleh Pete terhadap Jim yang membantu mengambil papan pendawa.

22. Jim dan Pete membantu Kelasi Pedang Langit mengamankan geladak. Mereka beruntung, menurunkan layar tepat pada waktunya. Sayang angin puting beliung itu tetap mematahkan salah satu tiang layar. (HSP:180)

Kutipan 1.22 menggambarkan Jim dan Pete membantu kelasi Pedang Langit untuk mengamankan geladak. Bentuk tolong menolong dilakukan oleh Jim dan Pete dengan membantu Kelasi Pedang Langit.

23. Laksmana Ramirez tanpa banyak bicara, langsung menebas tali-tali yang mengikat papan dan tiangtiang kerangkeng. Jim membantu melepaskan, Pete yang ikut membantu membuka kerangkeng setelah kakinya bebas. Hanya dalam hitungan detik kerangkeng tersebut roboh.(HSP:192)

Kutipan 1.23 menggambarkan Jim dan Pete membantu membebaskan kura-kura besar untuk dilepaskan dilaut. Bentuk tolong menolong dilakukan oleh Jim dan Pete membebaskan kurakura.

24. Sore hari. Laksamana Ramirez memutuskan untuk berlabuh. Penjelasan utusan tadi cukup. Ada yang harus dibantu. Urusan ini bukan tentang siapa yang benar siapa yang salah. Bukan pula pertikaian kepentingan. Penduduk kota Champa yang tidak berdosa harus dilindungi $(H S P: 202)$
Kutipan 1.24 menggambarkan Laksamana Ramirez memutuskan untuk membantu kota Chama yang terkena musibah. Bentuk tolong menolong dilakukan oleh penduduk kapal terhadap kota Champa.

25. Sekejap. Kepala adik baginda sudah mengelinding di atas lantai. Pedang Jim berhenti tepat sebelum menyentuh semilir pun leher jenjang Nayla. Gadis itu roboh saking terkejutnya. Jim buru-buru meraih pinggangnya. Mendekap. (HSP:219)

Kutipan 1.25 menggambarkan Jim membantu Nayla dari kejahatan Adik Baginda dengan menebas kepala Adik Baginda untuk menyelamatkan Nayla. Bentuk tolong menolong dilakukan Jim terhadap Nayla.

26. Jim punya kesibukan baru. Menjelajahi pedalaman hutan bersama Pete dan Laksamana Ramirez membantunya banyak menyembuhkan luka kota Champa. Kenangan-kenangan itu berhasil di kunci rapat dalam hatinya.

Kutipan 1.26 menggambarkan Pete dan Laksmana Ramirez banyak membantu Jim untuk melupakan kenangan-kenangnya dengan melakukan perjalanan baru dalam kehidupan Jim. Bentuk tolongmenolong yang dilakukan Pete dan Laksmana Ramirez terhadap Jim untuk membuang bekas luka lamanya.

27. "PERGILAH JIM... Aku mohon! Kau harus menyelesaikan dongengmu, kau harus membantu Laksamana menyelesaikan dongengnya. Bantulah dia. Biarkan aku menahan mereka " Suara Pete semakin purau. Ia mulai menangis pahanya semakin sakit. Mata Jim berkaca-kaca Pete mengacungkan pedangnya Pergilah!

Kutipan 1.27 menggambarkan Pete menyuruh Jim pergi meninggalkan dia agar bisa membantu Laksamana untuk menyelesaikan dongengnya, Pete akan melawan mahluk halus ini, bentuk tolong menolong dilakukan kepada Jim dan Laksamana ia rela berkorban nyawanya demi temannya menyelesaikan dongengnya.

\section{SIMPULAN}

Berdasarkan hasil penelitian dan pembahasan yang telah dijabarkan pada bab IV, maka dapat diambil kesimpulan bahwa di dalam novel Harga Sebuah Percaya karya Tere Liye terdapat nilai etika tolong menolong masyarakat. Nilai etika tolong menolong yang terdapat di dalam novel Harga Sebuah Percaya karya Tere Liye tergambar tokoh-tokoh di dalam novel memiliki sikap tolong menolong yang baik terhadap masyarakat. Hidup dalam masyarakat tolong menolong sangat penting guna menumbuhkan rasa memiliki dan keakraban antar masyarakat lainnya karena tolong menolong dibutuhkan oleh setiap manusia. Hal ini 
terlihat dari 27 kutipan. Selain tolong menolong antar tokoh juga memiliki rasa kasih sayang antar sesama.

\section{Saran}

Dalam sebuah karya sastra khusunya novel, tidak terlepas dari keinginan untuk mendapatkan suatu hal yang bermanfaat. Saran yang ingin penulis sampaikan dari hasil penelitian Harga Sebuah Percaya karya Tere Liye adalah sebagai berikut:

1. Disarankan guru Bahasa Indonesia dapat meningkatkan apresiasi sastra sehingga pembelajaran sastra lebih menarik dan diminati serta dapat dipergunakan juga sebagai masukan dalam memahami unsur-unsur ekstrinsik terhadap karya sastra terutama novel.

2. Disarankan terhadap sastrawan agar dapat menyuguhkan karyas sastra berbentuk novel yang didalamnya terdapat banyak nilai etika.

3. Disarankan bagi pembaca nilai-nilai etika yang terdapat dalam novel Harga Sebuah Percaya karya Tere Liye dapat dijadikan pedoman dalam hidup.

4. Disarankan penelitian ini dapat dijadikan acuan bagi peneliti berikutnya yang akan mengkaji objek peneltian yang sama maupun objek yang berbeda.

\section{DAFTAR PUSTAKA}

Abdullah, Yatimin. 2006. Pengantar Studi Etika I. Jakarta: Raja Grafindo Persada.

Liye, Tere. 2017. Harga Sebuah Percaya. Jakarta: Mahaka Publishing.

Noor, Juliansyah. 2011. Metodologi Penelitian. Jakarta: Perdana Media Grup.

Rafiek, M. 2010. Teori Sastra: Kajian Teori dan Praktik. Bandung: Rafika Aditama

Siswantoro, 2010. Metode Penelitian Sastra. Yogyakarta: Pustaka Pelajar

Siswantoro, 2014. Metode Penelitian Sastra. Yogyakarta: Pustaka Pelajar 